\title{
Evolution of the electrical and structural properties during the growth of Al doped ZnO films by remote plasma-enhanced metalorganic chemical vapor deposition
}

\section{Citation for published version (APA):}

Volintiru, I., Creatore, M., Kniknie, B. J., Spee, C. I. M. A., \& Sanden, van de, M. C. M. (2007). Evolution of the electrical and structural properties during the growth of Al doped ZnO films by remote plasma-enhanced metalorganic chemical vapor deposition. Journal of Applied Physics, 102(4), 043709-1/9. [043709]. https://doi.org/10.1063/1.2772569

DOI:

10.1063/1.2772569

Document status and date:

Published: 01/01/2007

\section{Document Version:}

Publisher's PDF, also known as Version of Record (includes final page, issue and volume numbers)

\section{Please check the document version of this publication:}

- A submitted manuscript is the version of the article upon submission and before peer-review. There can be important differences between the submitted version and the official published version of record. People interested in the research are advised to contact the author for the final version of the publication, or visit the DOI to the publisher's website.

- The final author version and the galley proof are versions of the publication after peer review.

- The final published version features the final layout of the paper including the volume, issue and page numbers.

Link to publication

\footnotetext{
General rights

- You may freely distribute the URL identifying the publication in the public portal. follow below link for the End User Agreement:

www.tue.nl/taverne

Take down policy

If you believe that this document breaches copyright please contact us at:

openaccess@tue.nl

providing details and we will investigate your claim.
}

Copyright and moral rights for the publications made accessible in the public portal are retained by the authors and/or other copyright owners and it is a condition of accessing publications that users recognise and abide by the legal requirements associated with these rights.

- Users may download and print one copy of any publication from the public portal for the purpose of private study or research.

- You may not further distribute the material or use it for any profit-making activity or commercial gain

If the publication is distributed under the terms of Article $25 \mathrm{fa}$ of the Dutch Copyright Act, indicated by the "Taverne" license above, please 


\title{
Evolution of the electrical and structural properties during the growth of Al doped ZnO films by remote plasma-enhanced metalorganic chemical vapor deposition
}

\author{
I. Volintiru, ${ }^{\text {a) }}$ M. Creatore, ${ }^{\text {b) }}$ and B. J. Kniknie \\ Department of Applied Physics, Eindhoven University of Technology, P.O. Box 513, 5600 MB Eindhoven, \\ The Netherlands \\ C. I. M. A. Spee \\ TNO Science and Industry, Materials Technology, P.O. Box 6235, 5600 HE Eindhoven, The Netherlands
}

M. C. M. van de Sanden

Department of Applied Physics, Eindhoven University of Technology, P.O. Box 513, 5600 MB Eindhoven, The Netherlands

(Received 15 March 2007; accepted 6 July 2007; published online 27 August 2007)

\begin{abstract}
Al-doped zinc oxide (AZO) films were deposited by means of remote plasma-enhanced metalorganic chemical vapor deposition from oxygen/diethylzinc/trimethylaluminum mixtures. The electrical, structural (crystallinity and morphology), and chemical properties of the deposited films were investigated using Hall, four point probe, x-ray diffraction (XRD), scanning electron microscopy (SEM), atomic force microscopy (AFM), electron recoil detection (ERD), Rutherford backscattering (RBS), and time of flight secondary ion mass spectrometry (TOF-SIMS), respectively. We found that the working pressure plays an important role in controlling the sheet resistance $R_{s}$ and roughness development during film growth. At $1.5 \mathrm{mbar}$ the AZO films are highly conductive $\left(R_{s}<6 \Omega / \square\right.$ for a film thickness above $\left.1200 \mathrm{~nm}\right)$ and very rough ( $>4 \%$ of the film thickness), however, they are characterized by a large sheet resistance gradient with increasing film thickness. By decreasing the pressure from 1.5 to $0.38 \mathrm{mbar}$, the gradient is significantly reduced and the films become smoother, but the sheet resistance increases $\left(R_{s} \approx 100 \Omega / \square\right.$ for a film thickness of $1000 \mathrm{~nm}$ ). The sheet resistance gradient and the surface roughness development correlate with the grain size evolution, as determined from the AFM and SEM analyses, indicating the transition from pyramid-like at 1.5 mbar to pillar-like growth mode at 0.38 mbar. The change in plasma chemistry/growth precursors caused by the variation in pressure leads to different concentration and activation efficiency of $\mathrm{Al}$ dopant in the zinc oxide films. On the basis of the experimental evidence, a valid route for further improving the conductivity of the AZO film is found, i.e., increasing the grain size at the initial stage of film growth. (C) 2007 American Institute of Physics. [DOI: 10.1063/1.2772569]
\end{abstract}

\section{INTRODUCTION}

Zinc oxide $(\mathrm{ZnO})$ has become a material of increasing interest in the last decade due to its remarkable properties, such as large exciton binding energy, piezoelectric character, nontoxicity, and high stability in plasma environment. Both in their undoped and doped form, $\mathrm{ZnO}$ films have many applications: the semiconductive $\mathrm{ZnO}$ can be used in thin film transistor and surface acoustic wave devices or as an epitaxial substrate for GaN. ${ }^{1}$ Highly conductive $n$-type doped $\mathrm{ZnO}$, on which we will focus in this article, is a transparent conductive oxide (TCO) which is studied as a valid alternative to the widely used tin-doped indium oxide (ITO) and $\mathrm{SnO}_{2}: \mathrm{F}$ for flat panel displays and solar cell applications. ${ }^{2-4}$ The p-type $\mathrm{ZnO}$ fabrication, necessary for $\mathrm{ZnO}$-based optoelectronic devices, has proven to be more difficult obtain due to the native $n$-type defects and low dopant solubility. ${ }^{5,6}$

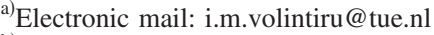

b) Author to whom correspondence should be addressed; electronic mail: m.creatore@tue.nl
}

Several dopants are used to achieve $n$-type doping in $\mathrm{ZnO}$, the most common being group III elements, such as B, $\mathrm{Al}, \mathrm{Ga}$, and In (Refs. 7 and 8) or F (Ref. 9) from the group VII. Among them, Al-doped $\mathrm{ZnO}(\mathrm{ZnO}: \mathrm{Al}$ or $\mathrm{AZO})$ is one of the most studied and can be obtained by different deposition techniques. The most reported deposition techniques are magnetron sputtering, ${ }^{10}$ pulsed laser deposition (PLD), ${ }^{11}$ while thermal chemical vapor deposition (CVD) ${ }^{12,13}$ and plasma-enhanced CVD (Ref. 14) are less common. Here we use a remote plasma enhanced metalorganic CVD (PEMOCVD) process to produce AZO films which have demonstrated suitable characteristics for front electrodes in thin film $a$-Si solar cell applications, i.e., high transmission ( $>80 \%$ ), low resistivity $\left(7 \times 10^{-4} \Omega \mathrm{cm}\right)$, and native roughness ( $>4 \%$ of the film thickness). ${ }^{15}$

As we will show later, our AZO films exhibit a strong sheet resistance gradient with increasing film thickness, i.e., the sheet resistance decreases from $180 \Omega / \square$ at $300 \mathrm{~nm}$ to $5.5 \Omega / \square$ at $1.3 \mu \mathrm{m}$. As demonstrated in a previous article, ${ }^{15}$ this is not detrimental for applications using $\mathrm{ZnO}$ as a substrate and where the films can be thicker than $1 \mu \mathrm{m}$, 
such as in $a$-Si:H solar cells. However, it can be a major disadvantage when $\mathrm{ZnO}$ is used as a top contact and deposited after the solar cell structure has been grown. Moreover, in solar cell applications at industrial scale, thinner films are desired because of cost issues. The gradient in sheet resistance might be typical for CVD techniques, being also observed in the case of the B-doped $\mathrm{ZnO}$ films deposited by low-pressure CVD. ${ }^{13}$ However, there have also been reports describing its presence, although to a much smaller extent, in the case of the AZO films deposited by PLD and physical sputtering. ${ }^{16,17}$ The presence of a gradient in sheet resistance may derive either from specific conditions, i.e., related to the substrate conditioning (e.g., deposition temperature, surface pretreatment, or external substrate bias), as well as from the plasma chemistry (working pressure and gas phase composition).

Presently, a large part of the research in the $\mathrm{ZnO}$ field is focused on improving the material properties addressing a specific application. The CVD literature contains only a limited amount of reports which describe in detail the evolution of different film parameters during the $\mathrm{ZnO}$ growth, i.e., with film thickness. ${ }^{18}$ Understanding how these parameters affect both the intrinsic properties of the film (amorphous versus polycrystalline, dopant level, etc.) and the extrinsic properties, such as grain size and film morphology development, eventually allow to design a process in which AZO layers with suitable $R_{s}$ and roughness for a specific application can be obtained.

In this work we chose to focus on the overall effect of the working pressure, which is found to be a key parameter in controlling the sheet resistance and film morphology of the Al-doped $\mathrm{ZnO}$ films under the deposition conditions presented in this work. By decreasing the pressure from 1.5 to 0.38 mbar a transition in the growth mode from pyramid-like to pillar-like, respectively, is observed. At the same time, the $\mathrm{Al}$ concentration is found to be lower in the case of the most conductive layers (1.5 mbar), pointing out different forms of $\mathrm{Al}$ incorporation in the two cases, due to a pressure-induced change in plasma chemistry. Controlling the grain growth and establishing the relation between the growth mode and the extrinsic/intrinsic film properties represents the main aim of this article. Based on this relationship we formulate a tentative growth model for the AZO films deposited at different pressures, by means of our remote PE-MOCVD technique.

\section{EXPERIMENTAL PROCEDURE}

\section{A. Plasma deposition setup}

To deposit Al-doped $\mathrm{ZnO}$ films we used an expanding thermal plasma ${ }^{19}$ generated in an argon-fed high pressure (360 mbar) cascaded arc. The plasma expands supersonically into a low pressure (0.3-1.5 mbar) deposition chamber, where diethylzinc $\left[\mathrm{Zn}\left(\mathrm{C}_{2} \mathrm{H}_{5}\right)_{2},(\mathrm{DEZ})\right]$, trimethylaluminium $\left[\mathrm{Al}\left(\mathrm{CH}_{3}\right)_{3},(\mathrm{TMA})\right]$ and oxygen are injected. Two separated injection rings, situated at 30 and $6.5 \mathrm{~cm}$ from the plasma source, are used for the injection of the metalorganics and oxygen, respectively. The liquid precursors, i.e., DEZ and TMA (Akzo Nobel, SSG grade), are evaporated at a constant
TABLE I. The typical experimental conditions used for the Al-doped $\mathrm{ZnO}$ film deposition.

\begin{tabular}{lcc}
\hline \hline Deposition parameter & Standard & Optimized \\
\hline Arc current $(\mathrm{A})$ & 50 & 50 \\
Ar flow $(\mathrm{sccm})$ & 1000 & 840 \\
$\mathrm{O}_{2}$ flow $(\mathrm{sccm})$ & 100 & 75 \\
DEZ flow $(\mathrm{g} / \mathrm{h})$ & 3.5 & 3.5 \\
TMA flow $(\mathrm{g} / \mathrm{h})$ & 0.28 & 0.28 \\
Pressure (mbar) & $0.38-1.5$ & 0.38 \\
Substrate temperature $\left({ }^{\circ} \mathrm{C}\right)$ & 200 & 200 \\
\hline \hline
\end{tabular}

rate by two controlled evaporating and mixing units from Bronkhorst HighTech B.V., which are heated up to $80{ }^{\circ} \mathrm{C}$ for DEZ and $100{ }^{\circ} \mathrm{C}$ for TMA, both using Ar as carrier gas. Films were deposited on $p$-type $c$-Si(100), $400 \mathrm{~nm}$ $\mathrm{SiO}_{2} / c-\mathrm{Si}$, and Corning glass substrates, which were chosen in order to make the different measurements possible, i.e., composition analysis, conductivity, and transmission, respectively. The typical precursor flows are reported in Table I. The substrate temperature was $200{ }^{\circ} \mathrm{C}\left( \pm 20{ }^{\circ} \mathrm{C}\right)$ during all depositions. The working pressure was varied in the $0.38-$ 1.5 mbar range by adjusting the pumping speed of the roots pump. Information about the stable species in the plasma was given by a differentially pumped AccuQuad mass spectrometer [Kurt Lesker; scanning electron microscopy (SEM) detector, electron ionization energy $70 \mathrm{eV}$, located at the substrate level.

\section{B. Film analysis}

A Phystech RH 2010 Hall effect measurement, a Jandel universal four point probe, and a Dektek 8 advanced development profiler were used to determine the films electrical properties and thickness, respectively. The morphological and structural properties of the deposited films were obtained with an NT-MDT Solver P47 atomic force microscopy (AFM) setup, a Philips XL 30 SEM and a Philips X-Pert SR 5068 powder diffractometer, equipped with a $\mathrm{Cu} K_{\alpha}$ source. To determine the film composition we used electron recoil detection (ERD) and Rutherford backscattering (RBS) measurements. The composition depth profile of all the samples was measured using a time of flight secondary ion mass spectrometry (TOF-SIMS) setup (IONTOF TOFSIMS IV) with $\mathrm{Bi}^{+}$as the analysis source and $\mathrm{Cs}^{+}$as the sputtered source, the area analyzed being $70 \times 70 \mu^{2}$.

\section{RESULTS}

\section{A. The influence of the working pressure on the resistivity evolution}

In order to perform ex situ analysis at different stages of growth, films with several thicknesses were deposited under identical conditions. The "standard" settings used to deposit this series are reported in Table I and were chosen on the basis of an optimization procedure performed to obtain the most conductive films at high pressure. The deposition rate under these standard conditions was found to decrease from $1.1 \mathrm{~nm} / \mathrm{s}$ at $1.5 \mathrm{mbar}$ to $0.7 \mathrm{~nm} / \mathrm{s}$ at $0.38 \mathrm{mbar}$ and is com- 


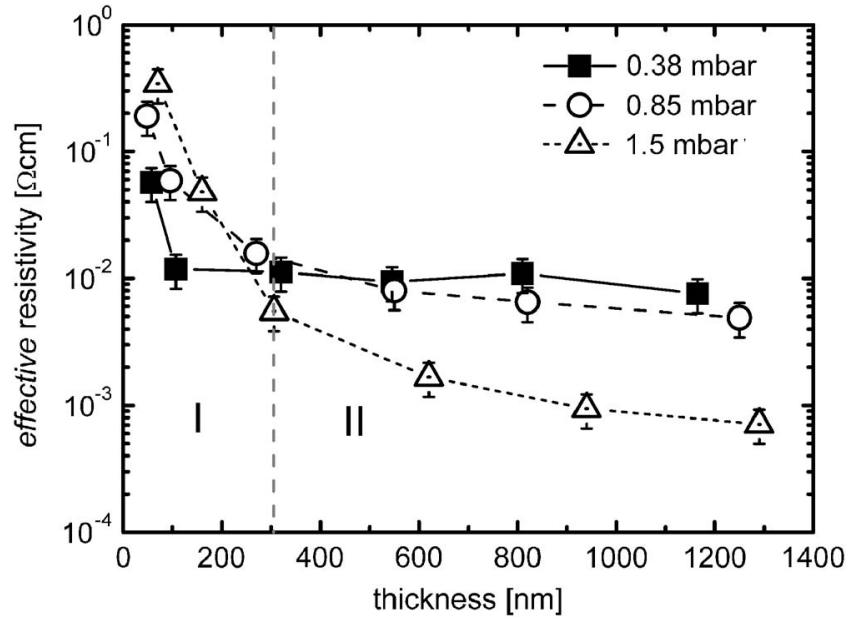

FIG. 1. Pressure influence on the effective resistivity $R_{s} d$ for the $\mathrm{ZnO}: \mathrm{Al}$ films, under standard conditions (see Table I).

parable to the rates obtained in other sputtering and CVD processes. ${ }^{17,20}$ Figure 1 shows the effective resistivity $\rho_{\text {eff }}(d)$, defined as

$$
\rho_{\mathrm{eff}}(d)=R_{s} d,
$$

as a function of film thickness for three different working pressures of 1.5, 0.85, and 0.38 mbar. In Eq. (1) $R_{s}$ is determined from four point probe measurements and the thickness is obtained using a step profiler. In addition, it can be observed that, by decreasing the working pressure from 1.5 to $0.38 \mathrm{mbar}$, the gradient in the effective resistivity is gradually reduced, until it almost disappears at the lowest pressure setting. The strong gradient in the first $100 \mathrm{~nm}$ is attributed to nucleation processes and occurs independently of the growth mode. Another remarkable feature of Fig. 1 is that there is a crossover, i.e., thick films (region II in Fig. 1) deposited at 0.38 mbar exhibit a much higher effective resistivity, 7.6 $\times 10^{-3} \Omega \mathrm{cm}$, compared to $5 \times 10^{-3} \Omega \mathrm{cm}$ for films deposited at $0.85 \mathrm{mbar}$ and $\sim 7 \times 10^{-4} \Omega \mathrm{cm}$ at $1.5 \mathrm{mbar}$, whereas in the thin film region (region I in Fig. 1) an opposite trend can be observed. The causes for these two types of behaviors will be analyzed in the remainder of the article, where, for simplicity, we will only address the two extreme deposition conditions: 1.5 mbar, defined as "high" and 0.38 mbar, defined as "low" pressure.

\section{B. Hall measurements}

The dominant carriers in the $\mathrm{ZnO}: \mathrm{Al}$ films, their concentration, and their mobility have been determined at room temperature from Hall measurements. For all films the $n$-type conductivity has been confirmed. As it can be observed in Fig. 2(a), the electron concentration, with a value of about $1.5 \times 10^{20} \mathrm{~cm}^{-3}$, is roughly constant during the film growth for both pressures, with slightly lower values for the films deposited at 0.38 mbar. The mobility trend, determined by combining these results with the effective resistivity in Fig. 1 , reveals a strong evolution, i.e., from $<1$ to $20 \mathrm{~cm}^{2} / \mathrm{V} \mathrm{s}$ at high pressure, compared to a smaller range, from $<2.5$ to $5 \mathrm{~cm}^{2} / \mathrm{V} \mathrm{s}$, at low pressure [Fig. 2(b)]. The very thin films $(<300 \mathrm{~nm})$ could not be measured with the Hall setup be-
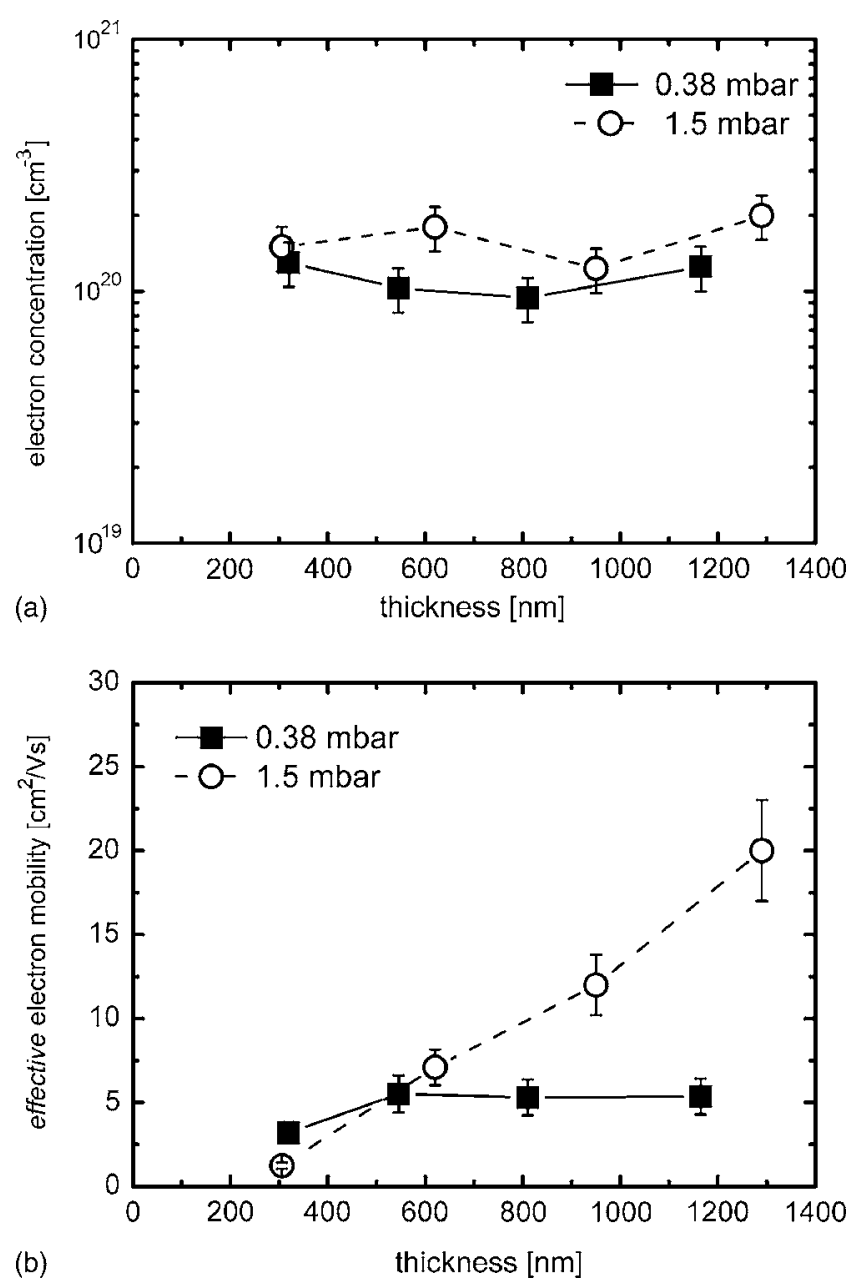

FIG. 2. Carrier concentration (a) and effective mobility (b) of the $\mathrm{ZnO}: \mathrm{Al}$ films, as determined with the Hall measurements, for films deposited at 1.5 and $0.38 \mathrm{mbar}$, under standard conditions (see Table I). Note: the very thin films $(\leq 300 \mathrm{~nm})$ could not be measured with the Hall setup.

cause the samples were too resistive. It is noteworthy that in solar cell applications a high mobility is preferred over a high carrier concentration because the latter induces light absorption in the near infrared region of the solar spectrum by free electrons, leading to lower cell efficiencies. ${ }^{17}$ Given this, it is important to investigate the origin of the gradient in both sheet resistance and mobility.

\section{Compositional measurements}

ERD/RBS measurements were performed to determine the composition of the AZO films deposited at low and high pressure. The results show stoichiometric films, with a $\mathrm{Zn:O}$ ratio of $1.00 \pm 0.01$. The $\mathrm{Al}$ dopant concentration is $\sim 0.65$ at. $\%$ at low pressure and $\sim 0.2$ at. $\%$ at high pressure. Impurities such as $\mathrm{C}$ and $\mathrm{H}$, if present, have concentrations below the ERD detection limit of 0.2 and 2 at. \%, respectively.

Additional information regarding the depth profiles of $\mathrm{ZnO}$ and $\mathrm{Al}$ is given by TOF-SIMS measurements shown in Fig. 3. Although the results are semiquantitative, it is clear that, in agreement with the ERD results, the $\mathrm{Al}$ content of films deposited at low pressure is significantly higher than at high pressure. Both depth profiles of $\mathrm{ZnO}$ and $\mathrm{Al}$ indicate a 


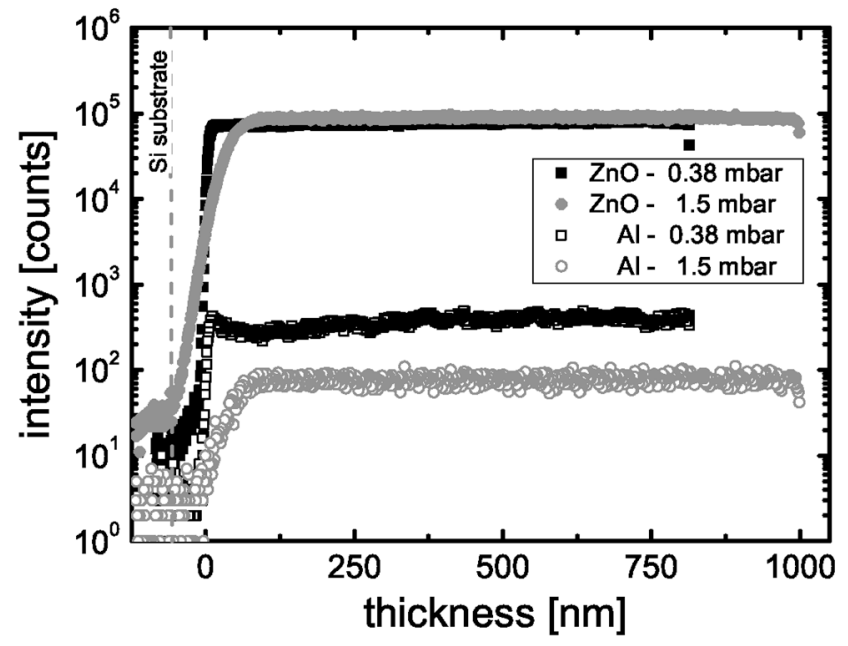

FIG. 3. SIMS measurements: $\mathrm{ZnO}$ and $\mathrm{Al}$ depth profiles of $\mathrm{ZnO}: \mathrm{Al}$ films deposited at 1.5 and 0.38 mbar, under standard conditions (see Table I).

constant bulk concentration of these elements throughout the film (Fig. 3), which is in accordance with the carrier concentration evolution with film thickness in Fig. 2(a). ${ }^{21}$

\section{Crystallinity and morphology}

$\mathrm{X}$-ray diffraction (XRD) measurements were used to determine the film crystallinity and estimate the average grain size. All $\mathrm{ZnO}$ :Al films were found to have $c$ axis, (002) preferential orientation [Fig. 4(a)]. From the full width at half maximum (FWHM) of the (002) peak, which is plotted in Fig. 4(b), values for the average grain size along the $c$ axis from $30 \mathrm{~nm}(0.38 \mathrm{mbar})$ to $45 \mathrm{~nm}(1.5 \mathrm{mbar})$ have been calculated using the simplified Scherrer equation. ${ }^{22}$ The average grain size in the growth direction was found to be constant during film growth [Fig. 4(b)] and is comparable with literature, ${ }^{23}$ showing good crystallinity of the AZO films.

The SEM and AFM measurements provided information on the film morphology and an estimation of the lateral grain size. The grain size, estimated from the top SEM images [Fig. 5(a)] and confirmed by AFM [Fig. 6(a)], ranges, for the thick films, from $50-150 \mathrm{~nm}$ at low pressure to $200-300 \mathrm{~nm}$ at high pressure. The values are lower for thin films, the difference with the thick films being more pronounced at high pressure [Figs. 5(a) and 6(a)]. ${ }^{24}$ From the crosssectional SEM pictures shown in Fig. 5(b), corroborated by Fig. 5(a), two types of growth for the $\mathrm{ZnO}$ films can be observed for the two cases: pillar-like at low pressure and pyramid-like at high pressure.

\section{E. Film roughness}

The root-mean-square (rms) value of the film roughness was calculated from the AFM images [Fig. 6(a)]. The results show rms values of $4 \%$ of the film thickness at $1.5 \mathrm{mbar}$, making them suitable for solar cell applications, as already demonstrated in previous research. ${ }^{14}$ On the contrary, much smoother films, with a rms below $1 \%$ of the thickness, can be deposited by decreasing the pressure to 0.38 mbar [Fig. 6(b)]. These films, although not very smooth yet, are prom-
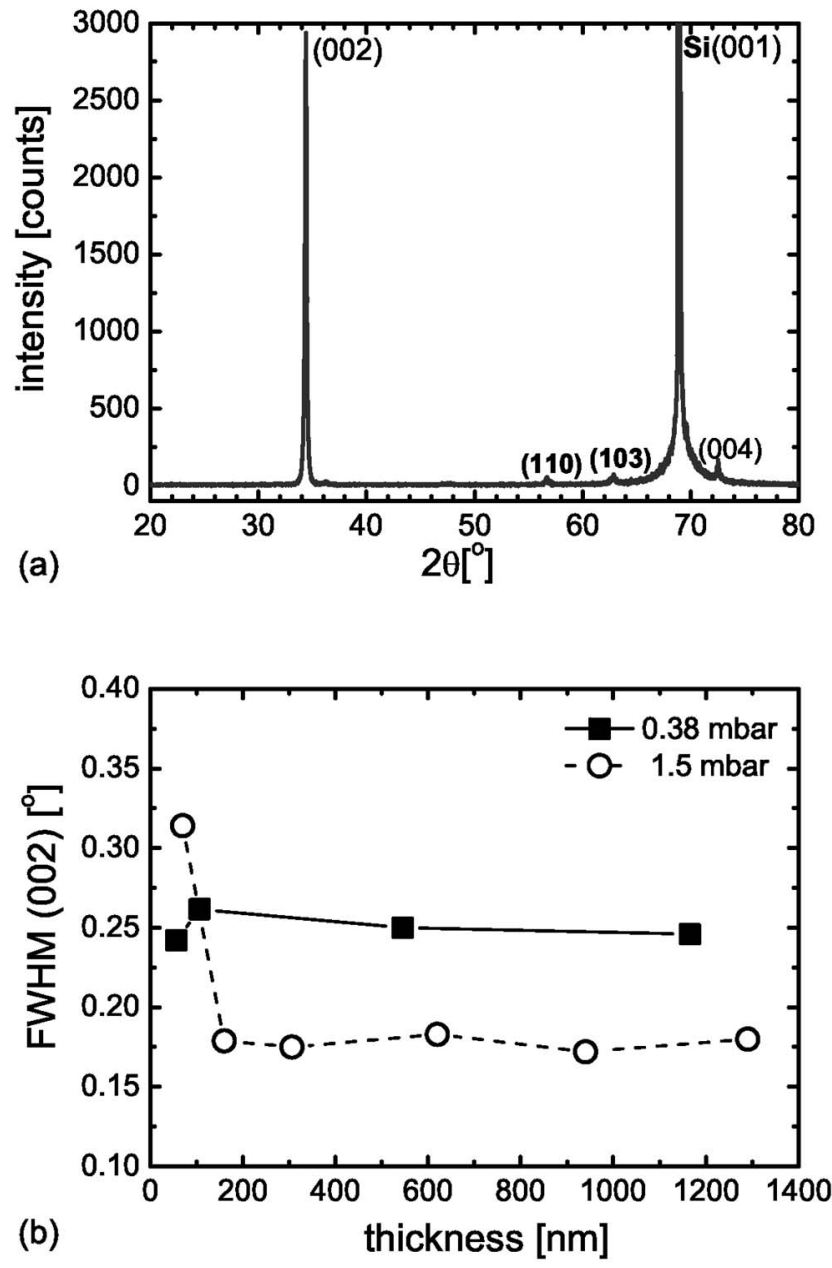

FIG. 4. (a) Typical XRD spectrum of a $600 \mathrm{~nm} \mathrm{ZnO}$ :Al film deposited at 1.5 mbar, under standard conditions (see Table I); (b) FWHM of the (002) peak, as determined from Lorentzian fit, for both $\mathrm{ZnO}$ :Al films deposited at 0.38 and 1.5 mbar.

ising, since the control of film roughness would allow us to extend the range of applications, to, e.g., optoelectronics. Being correlated with the grain size evolution, the rms roughness shows a strong development during the growth at 1.5 mbar and a very limited one at $0.38 \mathrm{mbar}$, as it can be observed in Fig. 6(b).

\section{DISCUSSION}

\section{A. Pressure influence on the $\mathrm{ZnO}$ film properties}

The effective resistivity, as determined from the four point probe and step profiler techniques and calculated according to Eq. (1), shows a strong development with film thickness (Fig. 1). It is important to notice that the effective resistivity represents an integrated value over the film thickness, i.e., the top resistivity is influenced by the underlying more resistive layers. The sheet resistance $R_{s}$ can, therefore, be related to the resistivity $\rho(x)$ at a film thickness $x$ by means of the following integral expression:

$$
\frac{1}{R_{s}(d)}=\int_{0}^{d} \frac{1}{\rho(x)} d x=\frac{d}{\rho_{\mathrm{eff}}(d)} .
$$

In order to determine the resistivity $\rho(d)$ from Eq. (2), we use the observed scaling of the effective resisitivity in a double 

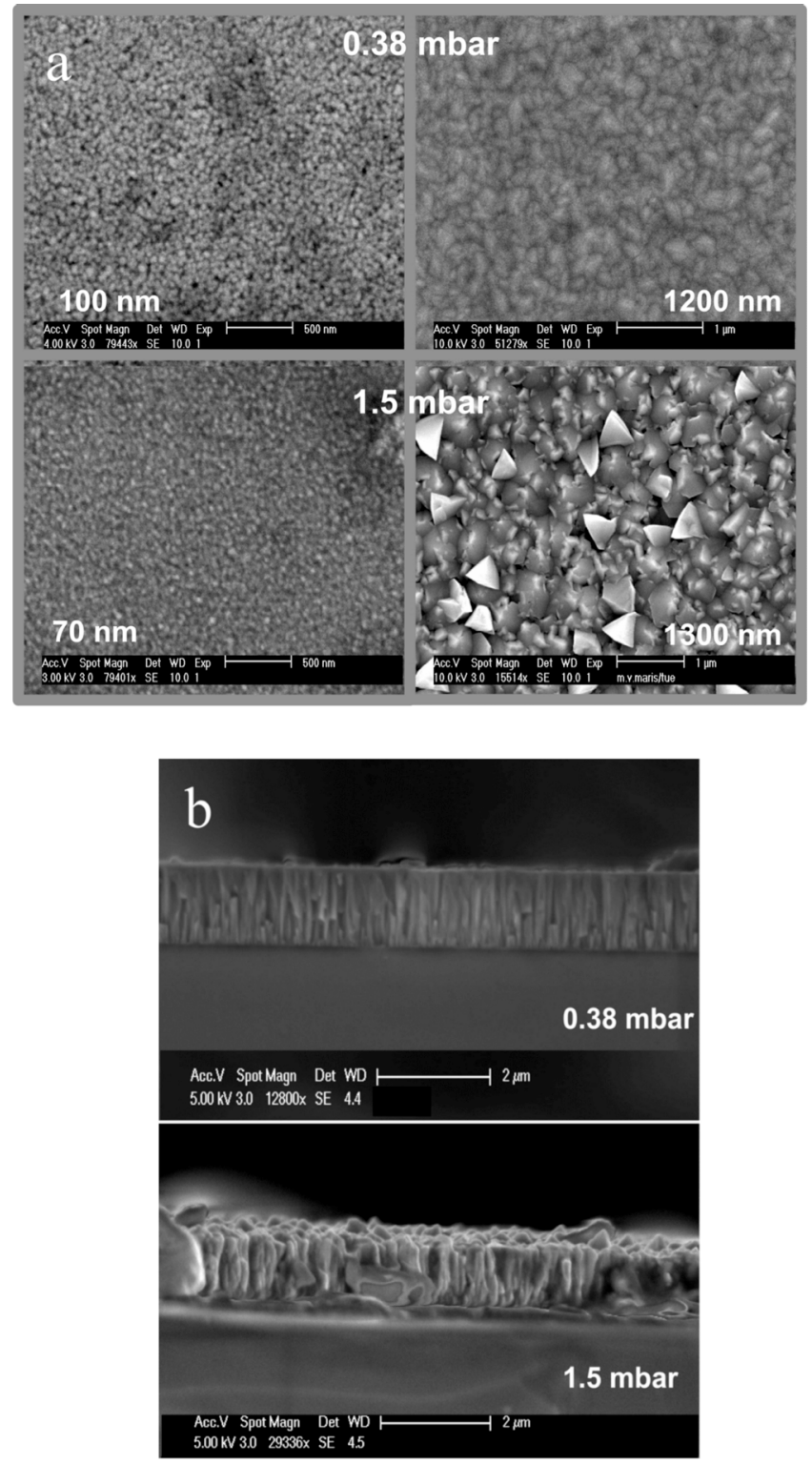

FIG. 5. Top SEM (a) and cross-sectional SEM (b) images of thin and thick $\mathrm{ZnO}: \mathrm{Al}$ films deposited at 1.5 and 0.38 mbar, under standard conditions (see Table I).

logarithmic plot, as shown in Fig. 10 from the Appendix

$$
\log \rho_{\text {eff }}(d) \propto a \log d .
$$

The resistivity $\rho(d)$ at a film thickness $d$, now a local property of the film as grown, using the scaling relation Eq. (3) equals

$$
\rho(d)=\frac{\rho_{\text {eff }}(d)}{a+1} .
$$

The derivation of Eq. (4), as well as the values for parameter $a$, are given in the Appendix. The resistivity $\rho(d)$ determined in this way is about three times lower than the effective resistivity, leading to a value of $\sim 2.2 \times 10^{-4} \Omega \mathrm{cm}$ at a thickness of $1200 \mathrm{~nm}$ for the films deposited at $1.5 \mathrm{mbar}$ (Table II). Note that Eq. (4) only corrects for the evolution of the sheet resistance with film thickness. Therefore, the result obtained indicates that the top part of our $\mathrm{ZnO}: \mathrm{Al}$ films is
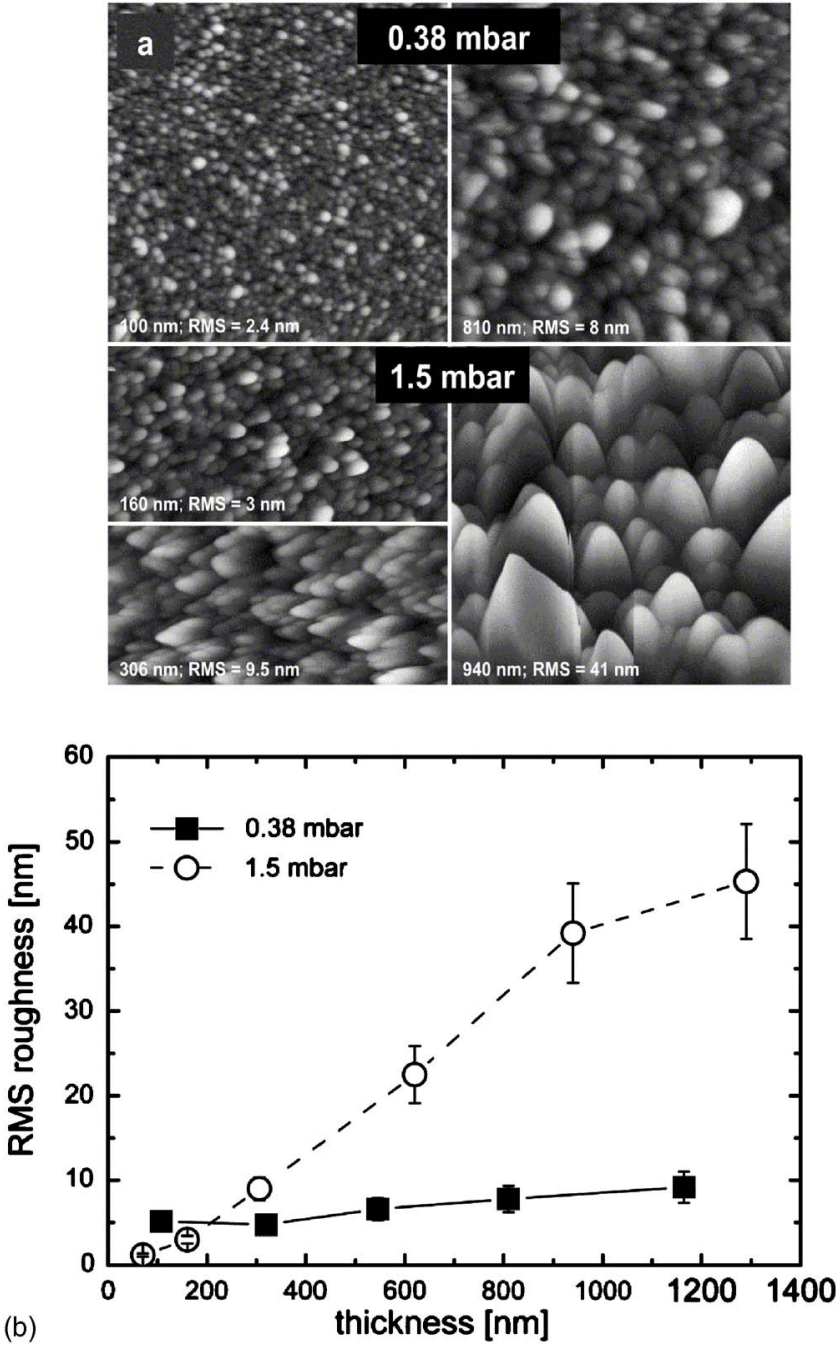

FIG. 6. rms roughness evolution with the $\mathrm{ZnO}$ :Al film thickness, deposited under standard conditions (see Table I), as resulted from AFM measurements.

very conductive and, consequently, very suitable for solar cell applications, when the front electrode ( $\mathrm{ZnO}: \mathrm{Al} \mathrm{film)} \mathrm{is}$ the substrate of the cell. At low pressure, similar to sputtering, almost no gradient is observed (Fig. 1) and, for these films, the resistivity equals the effective resistivity.

The resistivity gradient with thickness may generally be related to a gradient in carrier concentration and/or in carrier mobility with thickness. As shown in Fig. 2(a), in the present case the electron concentration is constant and, consequently,

TABLE II. The resistivity values $\rho(d)$ as a function of the film thickness $d$ of the Al-doped $\mathrm{ZnO}$ films deposited at $1.5 \mathrm{mbar}$, obtained according to the calculation in the Appendix.

\begin{tabular}{ccc}
\hline \hline $\begin{array}{c}d \\
(\mathrm{~nm})\end{array}$ & $\begin{array}{c}\rho_{\text {eff }} \\
(\Omega \mathrm{cm})\end{array}$ & $\begin{array}{c}\rho \\
(\Omega \mathrm{cm})\end{array}$ \\
\hline 70 & 0.34 & 0.11 \\
160 & $4.8 \times 10^{-2}$ & $1.5 \times 10^{-2}$ \\
306 & $5.5 \times 10^{-3}$ & $1.7 \times 10^{-3}$ \\
620 & $1.7 \times 10^{-3}$ & $5.3 \times 10^{-4}$ \\
940 & $9.4 \times 10^{-4}$ & $3.0 \times 10^{-4}$ \\
1290 & $7.1 \times 10^{-4}$ & $2.2 \times 10^{-4}$ \\
\hline
\end{tabular}


the resistivity gradient is entirely caused by a gradient in mobility [Fig. 2(b)]. This is also the case, to a much smaller extend, in the work of Agashe et al. ${ }^{17}$ In other cases, such as of Qu et al. ${ }^{25}$ both carrier concentration and mobility change during growth and a distinction cannot be made between the two parameters.

Therefore, by employing the scaling relation for the mobility trend, we obtain a value related to the top of the film which is about three times higher than the one measured by Hall in the high pressure case (cf. Appendix), i.e., $64 \mathrm{~cm}^{2} / \mathrm{V}$ s. This value is higher than the best mobility values reported in literature for the solar grade Al-doped $\mathrm{ZnO}$ films, ${ }^{17}$ reflecting the good quality of our Al-doped $\mathrm{ZnO}$ for solar cell applications. The mobility values reported here are related to the in grain as well as to the intergrain (grain boundary) contributions. In a future article we will demonstrate excellent in grain mobility values for the high pressure films ( $>100 \mathrm{~cm}^{2} / \mathrm{V} \mathrm{s}$ all through the growth), as determined by means of spectroscopic ellipsometry in the near infrared range.

The intergrain carrier mobility in polycrystalline Aldoped $\mathrm{ZnO}$ films is generally dependent on the grain boundary and ionized impurity scattering of the carriers ${ }^{26}$ and is, therefore, related to the grain size and/or the impurities segregated at the grain boundaries. The lateral grain size evolution shows a significant gradient at high pressure [Fig. 5(a)], which supports the mobility/resistivity evolution, as already mentioned in Sec. III D. The cross-sectional SEM pictures [Fig. 5(b)] show different growth modes at low and high pressure: pyramid-like at high pressure and pillar-like growth at low pressure, similar to previous results for undoped $\mathrm{ZnO}$ films. ${ }^{3}$

Apart from the morphological differences in growth modes, the pressure also influences the intrinsic properties of the material, via a change in the plasma chemistry/growth precursors. The $\mathrm{Al}$ concentration of $\sim 0.65$ at. $\%$ at low pressure and $\sim 0.2$ at. $\%$ at high pressure is opposite to what is expected if the resistivity values would solely depend on the dopant concentration. Assuming that the carrier concentration is only determined by the $\mathrm{Al}$ active as dopant, i.e., which donates one electron to the conduction band, we can calculate the percentage of the active $\mathrm{Al}$ to be about $96 \%$ at high pressure, compared to only $20 \%$ at low pressure. Together with the difference in $\mathrm{Al}$ concentration reported by $\mathrm{RBS} / \mathrm{ERD}$, this points toward a relation between plasma chemistry, species contributing to film deposition, and growth mode. Presumably, this leads to another form of $\mathrm{Al}$ incorporation at low pressure, inactive from electrical point of view, such as $\mathrm{AlO}_{x}$. Here we speculate that $\mathrm{AlO}_{x}$ may already be formed in the gas phase, due to the high reactivity of Al resulted from TMA decomposition in the plasma and under the hypothesis that a more oxidative environment develops at low pressure.

Another indication that the growth mechanism is different for the high and low pressure case is given by the behavior of film resistivity, as observed in regions I and II (Fig. 1), i.e., for thin films the resistivity is lower at low pressure, while for thick films the opposite trend is observed. We hypothesize that this is related to a higher nucleation density at low pressure (related to the growth species formed under these conditions), which is also suggested by the SEM measurements [Fig. 5(b)] and supported by the broad Si/AZO bulk interface found for $\mathrm{ZnO}$ and $\mathrm{Al}$ masses by TOF-SIMS measurements (Fig. 3).

The pressure has a significant influence on the AZO film growth, however, it cannot be separated from the precursor chemistry effect, because, in the PE-MOCVD process, a change in the pressure implies a simultaneous variation in the plasma chemistry, as we will discuss next.

\section{B. Influence of plasma chemistry on the $\mathrm{ZnO}$ film properties}

In order to separate the role of the plasma chemistry from the pressure, we compared AZO films at 0.38 mbar, deposited under two different experimental conditions, defined as "standard" and "optimized" (cf. Table I). Mass spectrometry measurements have been performed under these conditions, where $\mathrm{Ar}$ and $\mathrm{O}_{2}$ flow rates were progressively decreased. Such a decrease is accompanied by a decrease in consumption of molecular $\mathrm{O}_{2}$ in the plasma, which is defined by

$$
\Phi_{\mathrm{O}_{2}, \text { cons. }}=\frac{I_{\mathrm{O}_{2}, \text { gas }}-I_{\mathrm{O}_{2}, \text { plasma }}}{I_{\mathrm{O}_{2}, \text { gas }}} \Phi_{\mathrm{O}_{2}},
$$

where $\Phi_{\mathrm{O}_{2}}$ and $\Phi_{\mathrm{O}_{2} \text {, cons. }}$ are the flow rates of $\mathrm{O}_{2}$ in the gas mixture and the consumed $\mathrm{O}_{2}$ in the plasma, respectively, and $I_{\mathrm{O}_{2} \text {,gas }}$ and $I_{\mathrm{O}_{2} \text {,plasma }}$ are the mass spectroscopic signals of $\mathrm{O}_{2}$ in the absence and presence of a plasma, respectively. In the expanding thermal plasma, the $\mathrm{Ar}^{+}$ions and electrons, produced in the cascaded arc plasma source, are consumed by $\mathrm{O}_{2}$ injected downstream according to the charge exchange reaction (6a), followed by the dissociative recombination reaction (6b) (Ref. 27),

$$
\begin{aligned}
& \mathrm{Ar}^{+}+\mathrm{O}_{2} \rightarrow \mathrm{O}_{2}{ }^{*}+\mathrm{Ar}^{*}, \\
& \mathrm{O}_{2}^{+}+e \rightarrow \mathrm{O}+\mathrm{O}^{*} .
\end{aligned}
$$

As a result of these reactions and if $\mathrm{O}$ is also consumed in the film formation process, a decrease in both $\mathrm{Ar}$ and $\mathrm{O}_{2}$ flows leads to a decrease in the $\mathrm{O}_{2}$ consumption. As it can be seen from Fig. 7(a), this is correlated with an improvement in film conductivity. The oxygen-poor environment promotes the increase in $\mathrm{ZnO}$ film conductivity because in this condition film substoichiometry $(\mathrm{O} / \mathrm{Zn}<1)$ is achieved, as also earlier reported for undoped $\mathrm{ZnO}$ films. ${ }^{28}$

The sheet resistance gradient with film thickness was again investigated for these optimized conditions; the results, shown in Fig. 7(b), indicate that the sheet resistance gradient is partially recovered, which suggests that the plasma chemistry alone can influence the film growth, in particular the initial growth. The Al concentration decreases from 0.65 at. \% in the "standard" conditions to 0.45 at. \% in the "optimized" conditions, which, related to the electron concentration according to the explanation in Sec. IV A, leads to a higher active dopant percentage, of $35 \%$, compared with $20 \%$ in standard low pressure settings. The film roughness is smaller, i.e., $4 \mathrm{~nm}$ (optimized) compared with $7 \mathrm{~nm}$ (stan- 

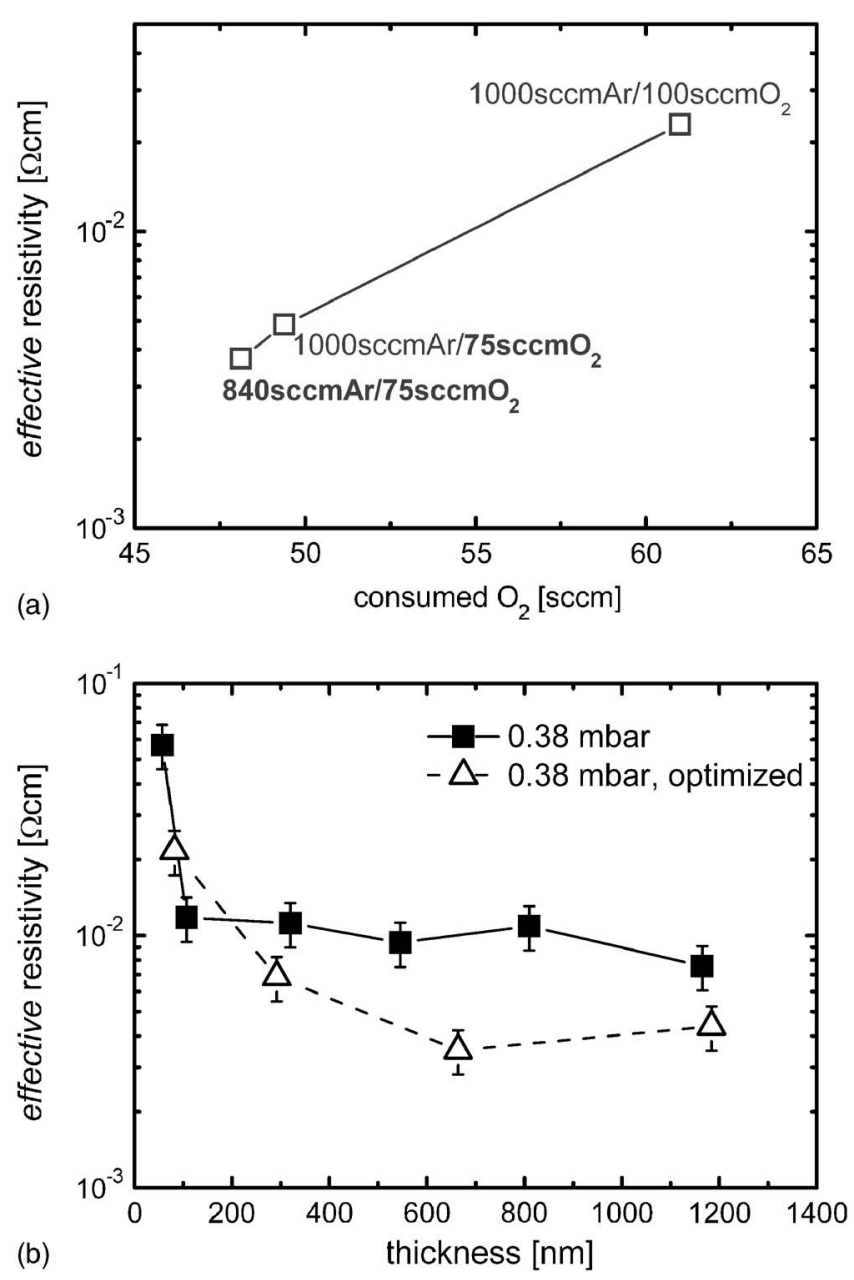

FIG. 7. Effective resistivity $R_{s} d$ dependence on the consumed $\mathrm{O}_{2}$ at 0.38 mbar (a); effective resistivity $R_{s} d$ evolution with thickness for $\mathrm{ZnO}$ :Al films, standard and optimized, at 0.38 mbar (b) (see Table I).

dard), for $600-700 \mathrm{~nm}$ thick films. This low rms value supports the observation that, by changing the plasma chemistry under constant pressure conditions, it is possible to lower the sheet resistance without switching to the other growth mode, i.e., pyramid-like growth.

\section{Tentative model for the $\mathrm{ZnO}$ film growth}

To summarize the obtained results, a tentative growth model for Al-doped $\mathrm{ZnO}$ grown using the ETP PE-MOCVD technique can be formulated. We should stress that, although we discuss this for our deposition technology, the tentative model presented here may be applied to other processes in which grains develop strongly during growth due to specific processing conditions or nucleation effects. In this particular case the initial growth is strongly influenced by the pressure and the plasma chemistry reflected in a difference in nucleation behavior. The nucleation density is much higher at low pressure, as indicated in region I of Fig. 1 and supported by the TOF-SIMS (Fig. 3) and SEM measurements (Fig. 5), probably due to a higher surface mobility and, perhaps, to a more favorable substrate chemistry of the growth precursors generated under these condition. After an initial incubation layer of about $150 \mathrm{~nm}$ for high pressure and $20 \mathrm{~nm}$ for low pressure films (TOF-SIMS profiles in Fig. 3), the film growth develops, pyramid-like (high pressure) and pillar-like (low pressure). During the first type of growth the grains compete with each other, some being suppressed and allowing others to develop as big pyramids for the thick film. In the second case, the pillars have room to develop independently resulting, therefore, in dense, more ordered and smoother films. Both types of growth are illustrated in Fig. 8. Due to a strong lateral grain development prevailing on the grain boundary scattering, the mobility becomes higher for high pressure films. In addition, the intrinsic properties are better in this case, due to a higher active dopant concentration. However, the sheet resistance for thin films depends strongly on the porous incubation layer, generally leading to higher values.

In order to improve the initial growth, there are several directions which can be undertaken, such as a substrate temperature increase, which is expected to promote surface mobility of the growth precursor or enhance nucleation site density, ${ }^{29}$ or the use of a $\mathrm{ZnO}$ buffer layer as substrate, which could increase the sticking of the precursor growth species causing a higher nucleation density. Preliminary experiments have already shown a factor of three improvements in sheet resistance for the AZO films deposited on a postannealed, resistive (undoped) $\mathrm{ZnO}$ buffer layer.
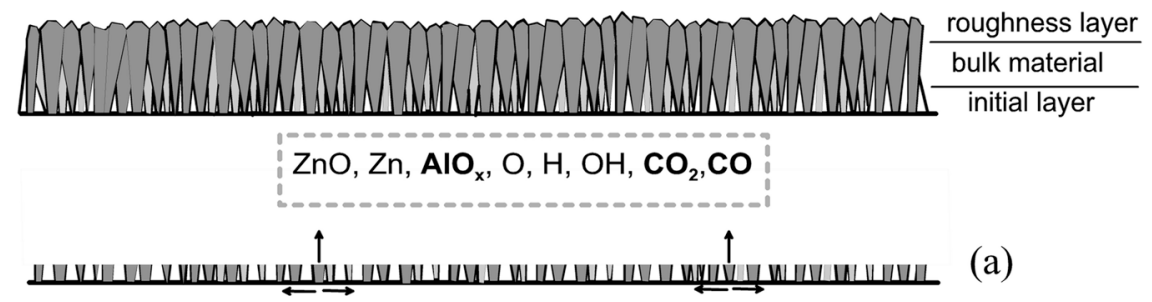

(a)

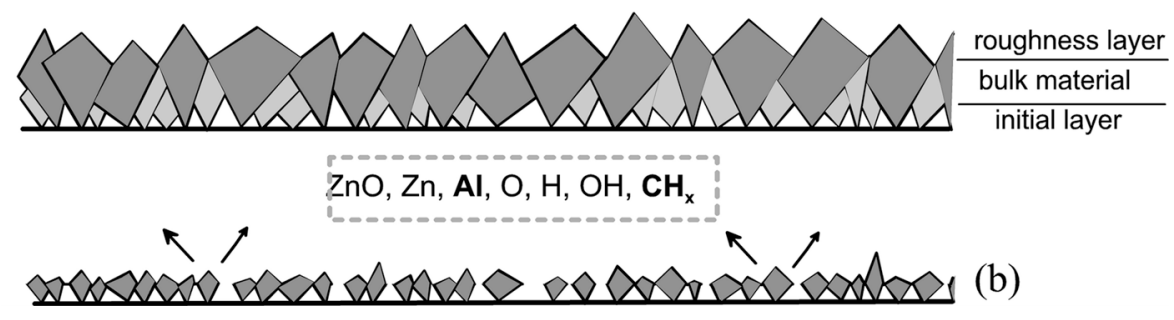

FIG. 8. A cartoon of tentative growth model for the initial and final growth of the $\mathrm{ZnO}: \mathrm{Al}$ films deposited at 0.38 (a) and 1.5 mbar (b); the lower parts of the pictures illustrate the initial stages of growth; the arrows represent the direction of the grain development. 


\section{CONCLUSIONS}

In this work AZO films were deposited by means of remote plasma-enhanced metalorganic chemical vapor deposition from oxygen/diethylzinc/trimethylaluminum mixtures. It has been shown that the working pressure plays an important role in the sheet resistance and roughness development during film growth. At 1.5 mbar the AZO films are characterized by a large sheet resistance gradient with film thickness and high rms values, i.e., $>4 \%$ of the film thickness. By decreasing the pressure from 1.5 to $0.38 \mathrm{mbar}$, this gradient is significantly reduced and the films become smoother, i.e. $<1 \%$ of the film thickness. The sheet resistance gradient and the surface roughness development correlate with the grain size evolution as determined from AFM and SEM analyses, indicating the transition from pyramid-like at $1.5 \mathrm{mbar}$ to pillar-like growth mode at 0.38 mbar. A low nucleation density at high pressure and a dense initial layer at low pressure, as suggested by TOF-SIMS measurements, are responsible for the lower initial sheet resistance of the AZO layers deposited at low pressure. Chemical analyses, i.e., ERD and TOF-SIMS, show a lower Al concentration in the case of the most conductive layers (high pressure). This indicates different forms of $\mathrm{Al}$ incorporation in the two cases, due to the change in plasma chemistry, induced by the change in working pressure. We have argued that the working pressure and the precursor species chemistry simultaneously affect the growth mode, in terms of initial growth (nucleation density) and grain development. In order to study the role of plasma chemistry independently, AZO films were deposited at constant pressure $(0.38 \mathrm{mbar})$ and variable argon and oxygen flows. The recovering of the resistivity gradient within the same growth mode indicates that the deposition precursor species influence the initial phase of the AZO film growth.

The control of film growth, i.e., sheet resistance gradient and surface roughness development is very important from an application point of view: the AZO films deposited at high pressure are successfully used as front contacts in $a-\mathrm{Si}: \mathrm{H}^{3}$ and can, possibly, be applied in $\mu c$-Si solar cells. However, the sheet resistance gradient with the thickness and the low nucleation density makes them unsuitable when the AZO films are deposited on the solar cell as a substrate, since in this case the initial sheet resistance is very important. A valid route for further improving the conductivity of the AZO film is increasing the grain size at the initial stage of film growth by increasing the substrate temperature or using a $\mathrm{ZnO}$ buffer layer as a substrate.

\section{ACKNOWLEDGMENTS}

The authors wish to thank Dr. W. M. Arnold Bik (Debye Institute, Utrecht University) for providing the ERD measurements and M. P. F. H. L. van Maris (Mechanical Engineering Department, TU/e) for the SEM measurements; M. J. F. van de Sande, J. F. C. Jansen, J. J. A. Zeebregts (TU/e), and G. Kirchner (TNO) are gratefully acknowledged for their technical assistance. This work was supported by the Netherlands Organization for Applied Scientific Research (TNO) and the Eindhoven University of Technology (TU/e) through the program for sustainable energy technology.

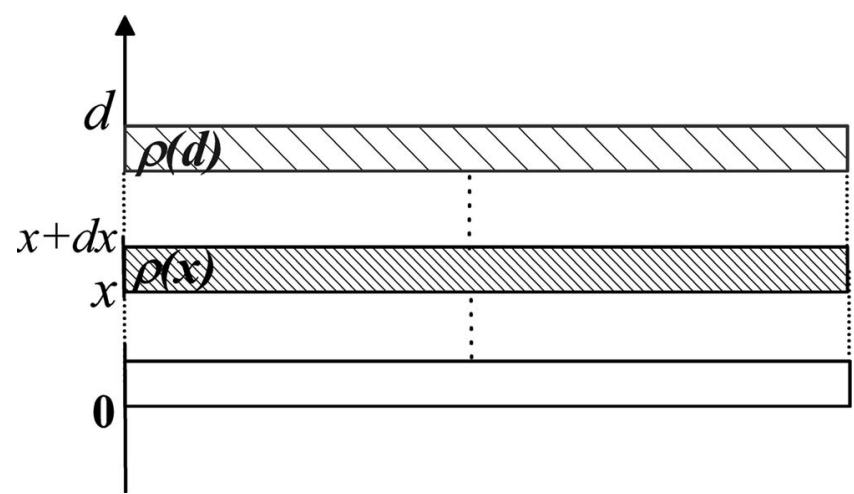

FIG. 9. Schematic representation of an AZO film as sequence of layers of infinitesimal thickness $d x ; \rho(x)$ and $\rho(d)$ denote the local resistivity at thickness $x$ and $d$, respectively.

\section{APPENDIX: CALCULATION OF REAL RESISTIVITY FROM THE FOUR POINT PROBE MEASUREMENT}

We consider the film as a sequence of layers of infinitesimal thickness $d x$ (Fig. 9). The measured sheet resistance of the layer with thickness $d$ is given by

$$
\frac{1}{R_{s}(d)}=\int_{0}^{d} \frac{1}{\rho(x)} d x=\frac{d}{\rho_{\mathrm{eff}}(d)}
$$

which defines the effective resistivity $\rho_{\text {eff }}$.

Rewriting Eq. (A1) in terms of the effective conductance $G_{\text {eff }}$ and conductivity $\sigma(x)=1 / \rho(x)$, we get

$$
G_{\mathrm{eff}}(d)=\int_{0}^{d} \sigma(x) d x=\frac{d}{\rho_{\mathrm{eff}}(d)} .
$$

From Eq. (A1) the $\sigma$ of the layer at thickness $d$ can be obtained as the derivative of the inverse effective resistivity $\rho_{\text {eff }}(x)$,

$$
\begin{aligned}
& \sigma(x)=\frac{\partial}{\partial x}\left[\frac{x}{\rho_{\mathrm{eff}}(x)}\right], \\
& \sigma(x)=\frac{1}{\rho_{\mathrm{eff}}(x)}-\frac{x}{\rho_{\mathrm{eff}}^{2}(x)} \frac{\partial \rho_{\mathrm{eff}}(x)}{\partial x}, \\
& \sigma(x)=\frac{1}{\rho_{\mathrm{eff}}^{2}(x)}\left[\rho_{\mathrm{eff}}(x)-x \frac{\partial \rho_{\mathrm{eff}}(x)}{\partial x}\right],
\end{aligned}
$$

leading to

$$
\frac{1}{\rho(x)}=\frac{1}{\rho_{\mathrm{eff}}(x)}+x \frac{\partial}{\partial x}\left[\frac{1}{\rho_{e f f}(x)}\right] .
$$

From Fig. 10 we conclude that the effective resistivity at different pressures scales as

$\log \rho(d) \propto a \log d$,

where $a$ is a constant determined from the slope in the double logarithmic plot. The substitution of Eq. (A7) into Eq. (A6) leads to a general expression for the resistivity 


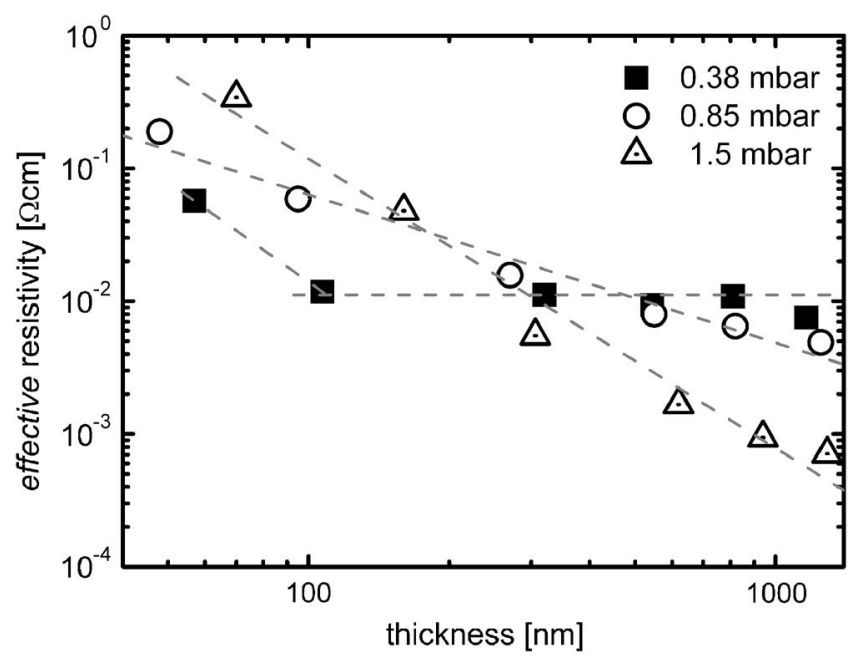

FIG. 10. Scaling behavior with thickness of the $\mathrm{ZnO}$ :Al film effective resistivity $R_{s} d$ at different pressures, under standard conditions (see Table $\mathrm{I}$ ).

$$
\rho(d)=\frac{\rho_{\mathrm{eff}}(d)}{a+1} .
$$

This means that $a$ can be determined for $p=0.85$ mbar and $p=1.5 \operatorname{mbar}(p=0.38$ mbar shows no development):

(i) 0.85 mbar: $a=1.1$,

(ii) 1.5 mbar: $a=2.2$.

Therefore, the resistivity $\rho(d)$ of the topmost layer equals:

(i) 0.85 mbar:

$$
\rho(d)=\frac{\rho_{\mathrm{eff}}(d)}{2.1},
$$

(ii) 1.5 mbar:

$$
\rho(d)=\frac{\rho_{\mathrm{eff}}(d)}{3.2} .
$$

The resistivity depends on the carrier concentration and mobility

$$
\rho \sim \frac{1}{n_{e} e \mu},
$$

where $e, n_{e}$, and $\mu$ represent the electronic charge, the electron density, and mobility, respectively. Note that $n_{e}$ is related to the $\mathrm{ZnO}$ stoichiometry and the doping level.

The mobility, under the assumption that $n_{e}$ is constant (Hall measurements), can be written as

$$
\mu(d)=(a+1) \mu_{\mathrm{eff}}(d)
$$

where $\mu_{\text {eff }}$ is the effective mobility (the outcome of the Hall measurements).

Therefore, the mobility $\mu(d)$ of the topmost layer equals:

(i) 0.85 mbar:

$$
\mu(d)=2.1 \mu_{\mathrm{eff}}(d)
$$

(ii) 1.5 mbar:

$$
\mu(d)=3.2 \mu_{\mathrm{eff}}(d) .
$$

${ }^{1}$ F. Hamdani, M. Yeadon, D. J. Smith, H. Tang, W. Kim, A. Salvador, A. E. Botchkarev, J. M. Gibson, A. Y. Polyakov, M. Skowronski, and H. Morkoç, J. Appl. Phys. 83, 983 (1998).

${ }^{2}$ L. Raniero, I. Ferreira, A. Pimentel, A. Gonçalves, P. Canhola, E. Fortunato, and R. Martins, Thin Solid Films 511-512, 295 (2006).

${ }^{3}$ R. Groenen, J. Löffler, J. L. Linden, R. E. I. Schropp, and M. C. M. van de Sanden, Thin Solid Films 492, 298 (2005).

${ }^{4}$ J. Müller, B. Rech, J. Springer, and M. Vanecek, Sol. Energy 77, 917 (2004).

${ }^{5}$ I. Volintiru, M. Creatore, W. H. van Helvoort, J. L. Linden, and M. C. M. van de Sanden, Appl. Phys. Lett. 89, 022110 (2006).

${ }^{6}$ A. Kobayashi, O. F. Sankey, and J. D. Dow, Phys. Rev. B 28, 946 (1983).

${ }^{7}$ W. W. Wenas, A. Yamada, K. Takahashi, M. Yoshino, and M. Konagai, J. Appl. Phys. 70, 7119 (1991).

${ }^{8}$ P. Nunes, E. Fortunato, P. Tonello, F. BrasFernandes, P. Vilarinho, and R. Martins, Vacuum 64, 281 (2002).

${ }^{9}$ I. Kim, K. Lee, T. S. Lee, J. Jeong, B. Cheong, Y. Baik, and W. M. Kim, J. Appl. Phys. 100, 063701 (2006).

${ }^{10}$ J. Hüpkes, B. Rech, O. Kluth, T. Repmann, B. Zwaygardt, J. Müller, R. Drese, and M. Wuttig, Sol. Energy Mater. Sol. Cells 90, 3054 (2006).

${ }^{11}$ H. Kim, A. Piqué, J. S. Horwitz, H. Murata, Z. H. Kafafi, C. M. Gilmore, and D. B. Chrisey, Thin Solid Films 377-378, 798 (2000).

${ }^{12}$ J. Hu and R. G. Gordon, J. Appl. Phys. 72, 5381 (1992).

${ }^{13}$ S. Fäy, L. Feitknecht, R. Schlüchter, U. Kroll, E. Vallat-Sauvain, and A. Shah, Sol. Energy Mater. Sol. Cells 90, 2960 (2006).

${ }^{14}$ A. Martín, J. P. Espinós, A. Justo, J. P. Holgado, F. Yubero, and A. R. González-Felipe, Surf. Coat. Technol. 151-152, 289 (2002).

${ }^{15}$ R. Groenen, J. Löffler, P. M. Sommeling, J. L. Linden, E. A. G. Hamers, R. E. I. Schropp, and M. C. M. van de Sanden, Thin Solid Films 392, 226 (2001).

${ }^{16}$ H. Tanaka, K. Ihara, T. Miyata, H. Sato, and T. Minami, J. Vac. Sci. Technol. A 22, 1757 (2004).

${ }^{17}$ C. Agashe, O. Kluth, J. Hüpkes, U. Zastrow, B. Rech, and M. Wuttig, J. Appl. Phys. 95, 1911 (2004).

${ }^{18}$ J. Hu and R. G. Gordon, J. Appl. Phys. 71, 880 (1992).

${ }^{19}$ M. C. M. van de Sanden, J. M. de Regt, and D. C. Schram, Plasma Sources Sci. Technol. 3, 501 (1994).

${ }^{20}$ Y. Li, G. S. Tompa, S. Liang, C. Gorla, Y. Lu, and J. Doyle, J. Vac. Sci. Technol. A 15, 1063 (1997).

${ }^{21}$ Because the exact etch rate of the AZO films is unknown, since it depends on their crystallinity and density, we report on the $x$ axis the thickness, as determined by means of profilometry, under the assumption that the etch rate is constant throughout the film.

${ }^{22}$ C. Suryanarayana and M. Grant Norton, X-Ray Diffraction-A Practical Approach (Plenum, New York, 1998).

${ }^{23}$ B. S. Li, Y. C. Liu, Z. S. Chu, D. Z. Shen, Y. M. Lu, J. Y. Zhang, and X. W. Fan, J. Appl. Phys. 91, 501 (2002).

${ }^{24}$ No conductive layer was deposited on top of the films for performing SEM analysis. Therefore, the contrast of the images in Fig. 5(a) gives qualitative information on the conductivity of the films: higher contrast is obtained due to less charging during the analysis, i.e., when the films are more conductive.

${ }^{25}$ Y. Qu, T. A. Gessert, K. Ramanathan, R. G. Dhere, R. Noufi, and T. J. Coutts, J. Vac. Sci. Technol. A 11, 996 (1993).

${ }^{26}$ S. Ghosh, A. Sarkar, S. Chandhuri, and A. K. Pal, Thin Solid Films 205, 64 (1991).

${ }^{27}$ M. F. A. M. van Hest, J. R. Haartsen, M. H. M. van Weert, D. C. Schram, and M. C. M. van de Sanden, Plasma Sources Sci. Technol. 12, 539 (2003).

${ }^{28}$ R. Groenen, H. Linden, and M. C. M. van de Sanden, Plasma Processes Polym. 2, 618 (2005).

${ }^{29}$ R. F. Xiao, J. Alexander, and F. Rosenberger, Phys. Rev. A 43, 2977 (1991). 